\title{
Modyfikacja powierzchni stali przez natapianie pasty $\mathrm{BNi}-2$
}

\author{
Modification of the steel surface \\ by surfacing the paste BNi-2
}

\section{Streszczenie}

W artykule opisano metodę modyfikacji powierzchni stali, wykorzystującą jako materiał powłoki i źródło pierwiastków dyfundujących lut twardy. Lut po wygrzaniu w piecu próżniowym tworzy wielofazową powłokę o zwiększonej twardości w stosunku do materiału podłoża. W ramach pracy przeprowadzono próby modyfikacji stali z wykorzystaniem pasty na bazie niklu o oznaczeniu BNi-2. Celem badań było określenie właściwości powłoki otrzymanej po procesie modyfikacji oraz ocena strefy dyfuzyjnej powłoka - podłoże.

Słowa kluczowe: Modyfikacja powierzchni, natapianie, lut twardy $\mathrm{BNi}-2$

\section{Abstract}

This article describes a method of modifying the surface of the steel using the brazing alloy as a coating material and a source of diffusing elements. The brazing alloy after soaking in a vacuum furnace forms a multiphase coating of increased hardness in relation to the base metal. Attempts to modify the steel with a paste based on nickel - BNi-2 were carried out. The purpose of the study was to determine the properties of the coating resulting from the modification process and the evaluation of the diffusion zone.

Keywords: Surface modification, surfacing, brazing alloy $\mathrm{BNi}-2$

\section{Wstęp}

Rosnące wymagania stawiane przez współczesną technikę wymuszają podejmowanie i prowadzenie prac badawczych mających na celu poprawę trwałości oraz niezawodności części maszyn i urządzeń. Zużycie elementów maszyn spowodowane tarciem prowadzi do znacznych strat ekonomicznych, dlatego uzasadnione jest podejmowanie działań mających na celu zwiększenie odporności części na zużycie ścierne. Może się to odbywać poprzez zastosowanie nowych materiałów lub poprawę właściwości obecnie stosowanych, np. przez modyfikację składu chemicznego, struktury lub też przez modyfikację powierzchni.

Jednym z kierunków działań mających na celu poprawę właściwości stalowych części maszyn jest modyfikacja objętościowa przez wprowadzanie odpowiednich pierwiastków stopowych. Pozwala to na polepszenie właściwości wskutek zmiany cech osnowy oraz regulację udziału, rodzaju, kształtu, wielkości i rozmieszczenia faz tworzących strukturę stopów [1].

Innym kierunkiem jest modyfikacja powierzchni elementów, bowiem o jakości, trwałości i właściwościach eksploatacyjnych decyduje $w$ znacznym stopniu war- stwa powierzchniowa materiału [2].

W dziedzinie inżynierii powierzchni obserwuje się ciągłe zainteresowanie warstwami wierzchnimi i powłokami na stalowych częściach maszyn i narzędzi. Pomimo znaczących osiągnięć w stosowaniu nowych metod i technik wytwarzania warstw powierzchniowych, istnieje ciągłe zapotrzebowanie przemysłu na tradycyjne technologie wytwarzania twardych warstw i powłok na narzędziach oraz częściach maszyn. Technologie te charakteryzują się bowiem prostotą wykonania i niskim kosztem, co niekiedy jest bardzo ważnym kryterium, determinującym wybór danej metody [3]. Jedną z metod wytwarzania powłok jest modyfikacja z wykorzystaniem lutów twardych, będąca $w$ fazie opracowywania i badania w Instytucie Mechaniki Precyzyjnej w Warszawie.

\section{Modyfikacja powierzchni stali z wykorzystaniem lutów twardych}

Modyfikacja powierzchni stali z wykorzystaniem lutów twardych jest procesem wieloetapowym, łączącym w sobie wygrzewanie części z naniesioną

Mgr inż. Adam Kondej, dr hab. inż Tomasz Babul - Zakład Obróbki Cieplnej, Instytut Mechaniki Precyzyjnej. 
roztopioną warstwą lutu oraz objętościową obróbkę cieplną podłoża. Modyfikacja ma na celu zwiększenie twardości powierzchniowej i odporności na zużycie ścierne elementów wykonanych ze stali średnioi wysokowęglowych stopowych [4].

Pierwszy etap procesu modyfikacji polega na nałożeniu warstwy lutu na powierzchnię materiału modyfikowanego i wygrzaniu elementu w temperaturze umożliwiającej stopienie lutu i dobre zwilżenie powierzchni podłoża. Czas procesu wygrzewania wynosi kilka godzin. Temperatura topnienia nakładanego materiału musi być niższa niż temperatura topnienia podłoża, aby powierzchnia podłoża nie uległa nadtopieniu.

W pierwszym etapie modyfikacji można wyróżnić dwa rodzaje zjawisk: adhezyjne i dyfuzyjne. Zjawiska adhezyjne obejmują kontakt fizyczny oraz chemiczny między powierzchnią materiału modyfikowanego i ciekłym lutem. Na tym etapie ważną rolę pełnią takie zjawiska jak zwilżalność i rozpływność (rys. 1). Jeżeli ciekły lut oddziałuje z materiałem podłoża, to po zjawisku adhezji zachodzi dyfuzja. Od temperatury i czasu wygrzewania zależy to, do jakiej głębokości zachodzi wzajemna dyfuzja atomów lutu i materiału podłoża. Im dłuższy czas procesu, tym większa głębokość strefy dyfuzji. Temperaturę procesu dobiera się w zależności od temperatury likwidusu zastosowanego lutu. Dla lutów na bazie Ni wynosi ona powyżej $1000{ }^{\circ} \mathrm{C}$. Po zakończeniu procesu wygrzewania następuje chłodzenie wraz z piecem przy obniżonym ciśnieniu komory.

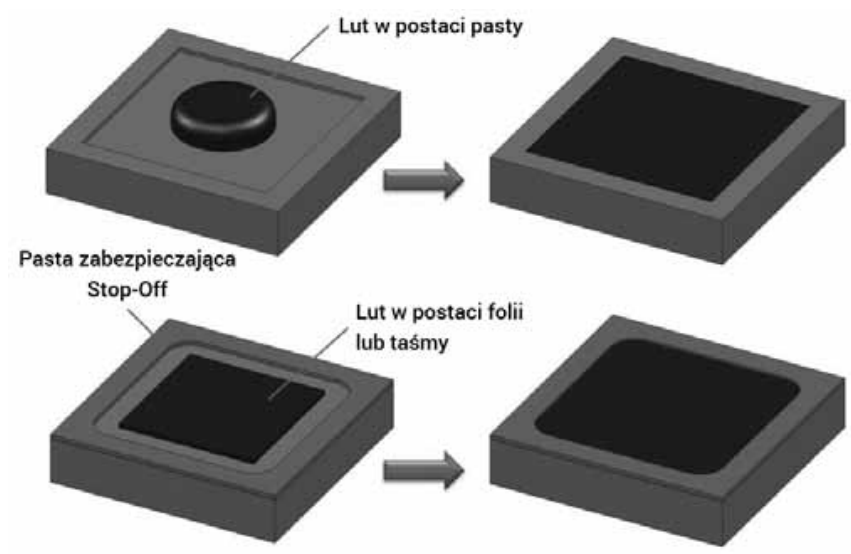

Rys. 1. Schemat zwilżania i rozpływania lutowia podczas natapiania lutów w różnej formie

Fig. 1. Diagram of wetting and spilling of the brazing alloy during surfacing for various forms of brazing alloys

Zastosowany do procesu modyfikacji lut powinien wykazywać powinowactwo metalurgiczne z zastosowaną stalą [5]. Najlepiej, gdy tworzy z nią roztwory stałe umocnione wydzieleniowo, ponieważ wtedy powłoka charakteryzuje się dobrą przyczepnością i wysoką odpornością na uszkodzenia mechaniczne.
Drugi etap modyfikacji polega na obróbce cieplnej elementu z naniesioną powłoką. Konieczność prowadzenia tej obróbki związana jest z tym, że w czasie procesu wytwarzania powłoki (proces przebiega w wysokiej temperaturze w ciągu kilku godzin) zachodzą zmiany strukturalne powodujące to, że podłoże stalowe pod warstwą wierzchnią może uzyskać gruboziarnistą strukturę i w konsekwencji niewystarczającą wytrzymałość w warunkach dużych obciążeń. Rodzaj obróbki oraz parametry procesu dobiera się odpowiednio do gatunku modyfikowanej stali.

\section{Cel badań}

Celem przeprowadzonych badań było wytworzenie powłoki przy użyciu lutu BNi-2 w postaci pasty na stali średniowęglowej stopowej i określenie jej mikrostruktury oraz właściwości, ze szczególnym uwzględnieniem strefy dyfuzji powłoka - podłoże. Badania miały charakter wstępny i służyły do walidacji opracowywanej metody modyfikacji powierzchni stali dla przyjętych założeń materiałowych oraz parametrów technologicznych.

\section{Przedmiot badań}

Przedmiotem badań była powłoka modyfikująca powierzchnię stali 42CrMo4. Skład chemiczny stali przedstawiono w tablicy I. Tego gatunku stal stosowana jest głównie do produkcji elementów maszyn wymagających bardzo dużej wytrzymałości, jak koła zębate, wały, wirniki, osie itd. Stale tego rodzaju należą do metali trudnospawalnych. Zastosowana stal stanowiła modelowe podłoże, służące do wytworzenia na jej powierzchni wielofazowej powłoki.

Do przeprowadzenia prób modyfikacji powierzchni stali z wykorzystaniem lutów konieczne było wykonanie odpowiednich próbek. Zostały one wytoczone z pręta o średnicy $\emptyset 25 \mathrm{~mm}$ i miały postać krążków z wybraniem o średnicy $\varnothing 22 \mathrm{~mm}$ i głębokości $1 \mathrm{~mm}$, w którym na oczyszczonej i odtłuszczonej powierzchni umieszczano lut w postaci pasty. Kształt próbek miał na celu ograniczenie rozpływności lutowia (rys. 2). Tak przygotowane próbki umieszczono w piecu próżniowym i poddawano wygrzewaniu.

Stopy Ni-Cr-B-Si są stosowane do lutowania twardego oraz jako materiał do modyfikacji powierzchni w celu nadania jej większej odporności na zużycie ścierne. Znajdują zastosowanie w przemyśle lotniczym, energetycznym, chemicznym. Szeroki zakres zastosowań stopów Ni-Cr-B-Si jest spowodowany ich dobrymi właściwościami, dzięki dodatkowi boru oraz krzemu. Lutami z tej grupy są luty z serii BNi, dostępne

Tablica I. Skład chemiczny stali 42CrMo4 - wyniki spektroskopii optycznej [4]

Table I. The chemical composition of the steel 42CrMo4 - results of optical spectroscopy [4]

\begin{tabular}{|c|c|c|c|c|c|c|c|c|c|c|c|c|}
\hline \multicolumn{10}{|c|}{ Skład chemiczny [\% wag.] } \\
\hline C & Si & Mn & P & S & Cr & Mo & Ni & Al & Co & Cu & V & W \\
\hline 0,42 & 0,22 & 0,61 & 0,01 & 0,005 & 1,02 & 0,16 & 0,11 & 0,01 & 0,004 & 0,16 & $<0,0011$ & $<0,01$ \\
\hline
\end{tabular}


na rynku w postaci pasty, taśmy oraz folii. Są to luty twarde przeznaczone do łączenia stali nierdzewnych, żaroodpornych stopów niklu oraz stali stopowych [6].

Jako materiał do wytworzenia powłoki wybrano lut na bazie Ni - BNi-2 (AMS 4777) w postaci pasty. Skład chemiczny oraz jego temperatury likwidus i solidus przedstawiono w tablicy II.

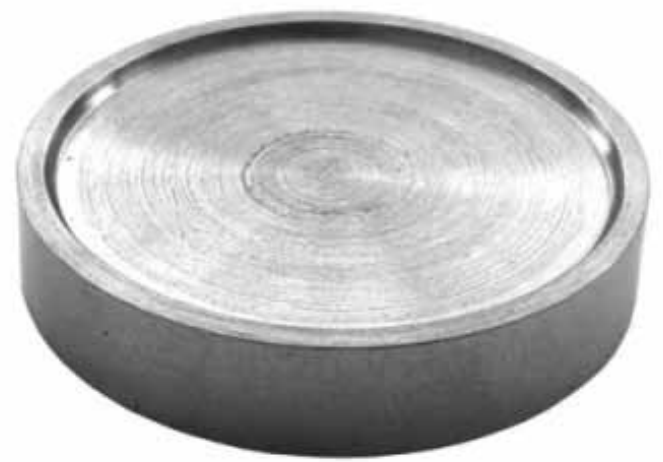

Rys. 2. Próbka stalowa przeznaczona do modyfikacji powierzchni [4] Fig. 2. The steel sample intended for surface modification [4]

\section{Parametry procesu}

Parametry procesu natapiania i wygrzewania lutu na powierzchni stali w piecu próżniowym (rys. 3) zamieszczono w tablicy III. Czasy wygrzewania próbek w komorze próżniowej $\mathrm{w}$ temperaturze $1050{ }^{\circ} \mathrm{C}$ wynosiły odpowiednio: $t_{1}=1 h, t_{2}=2 h, t_{3}=4 h, t_{4}=8 h$.

Po wygrzewaniu w piecu próżniowym próbki pokryte lutem zostały zahartowane w oleju. Zabieg hartowania miał na celu ocenę jakości połączenia powłoki z podłożem o strukturze martenzytycznej oraz sprawdzenie, czy nie wystąpiło zjawisko delaminacji powłoki.

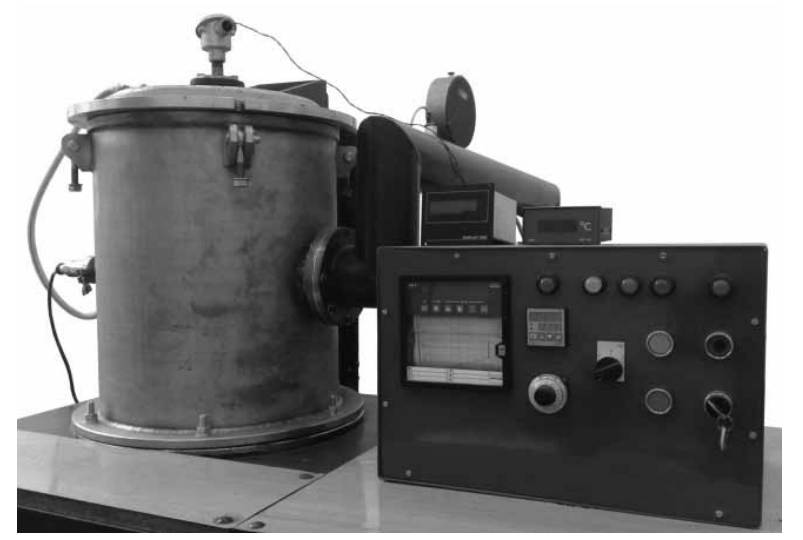

Rys. 3. Piec próżniowy wykorzystywany do modyfikacji stali [4] Fig. 3. The vacuum furnace used for steel modification [4]

\section{Metodyka badań}

Praca obejmowała swoim zakresem badania strukturalne na mikroskopie metalograficznym oraz badania rozkładu twardości.

Powierzchnie zgładów szlifowano, polerowano, a następnie trawiono Nitalem. Tak przygotowane próbki poddano obserwacjom na mikroskopie Olympus IX70 przy powiększeniach do 1000x. Charakterystyczne obszary fotografowano i mierzono wybrane wielkości elementów struktury.

Rozkłady twardości metodą Vickersa HV0,025 sporządzono na przekrojach w obszarze powłoki, strefy dyfuzji oraz materiału podłoża przy użyciu automatycznego twardościomierza Struers DuraScan 70.

\section{Wyniki badań}

Na rysunkach 4 i 5 przedstawiono obrazy mikroskopowe próbek modyfikowanych lutem BNi-2. Na rysunku 4 widoczna jest mikrostruktura stali oraz powłoki po procesie wygrzewania przez 8 godzin, na rysunku 5 po procesie wygrzewania przez 8 godzin wraz z późniejszym hartowaniem.
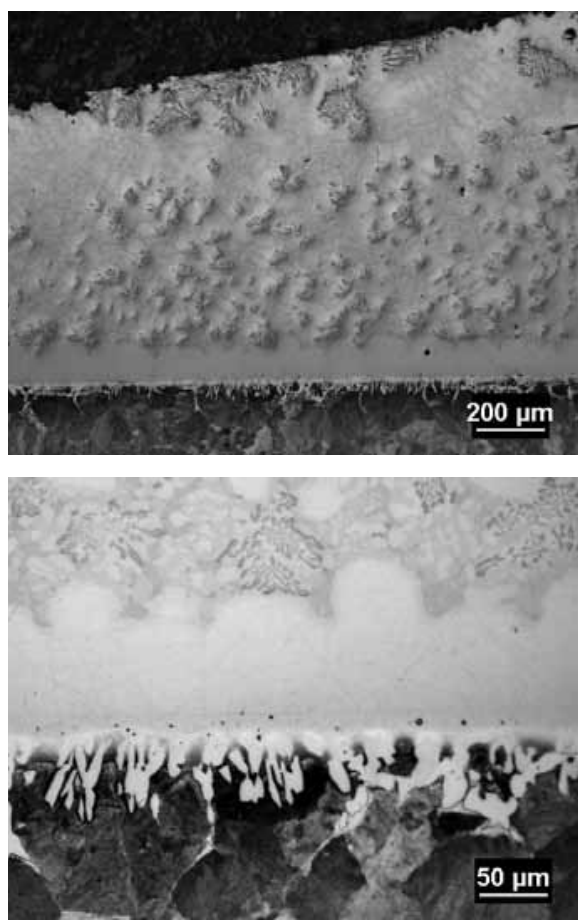

Rys. 4. Zdjęcia mikroskopowe próbki natapianej lutem BNi-2 i wygrzewanej przez 8 godzin

Fig. 4. Microscopic images of the sample after surfacing with BNi-2 and soaking for 8 hours

Tablica III. Parametry procesu wygrzewania lutu Table III. Parameters of soaking process wanego lutu [7]

Table II. The chemical composition, the solidus and liquidus temperature of the used brazing alloy [7]

\begin{tabular}{|c|c|c|c|c|c|c|c|}
\hline \multirow{2}{*}{ Nazwa lutu } & \multicolumn{5}{|c|}{$\begin{array}{c}\text { Zawartość pierwiastków } \\
\text { [\% wag.] }\end{array}$} & $\begin{array}{c}\text { Temp. } \\
\text { solidus } \\
{\left[{ }^{\circ} \mathrm{C}\right]}\end{array}$ & $\begin{array}{c}\text { Temp. } \\
\text { likwidus } \\
{\left[{ }^{\circ} \mathrm{C}\right]}\end{array}$ \\
\cline { 2 - 5 } & $\mathrm{Cr}$ & $\mathrm{Fe}$ & $\mathrm{Si}$ & $\mathrm{B}$ & $\mathrm{Ni}$ & & 999 \\
\hline $\begin{array}{c}\text { AWS BNi-2/ } \\
\text { AMS 4777 }\end{array}$ & 7 & 3 & 4,5 & 3,2 & reszta & 971 & 999 \\
\hline
\end{tabular}

\begin{tabular}{|c|c|}
\hline Temperatura $\left[{ }^{\circ} \mathrm{C}\right]$ & 1050 \\
\hline $\begin{array}{c}\text { Szybkość nagrzewania } \\
{\left[{ }^{\circ} \mathrm{C} / \mathrm{min}\right]}\end{array}$ & 15 \\
\hline Czas $[\mathrm{h}]$ & $\mathrm{t}_{1}=1, \mathrm{t}_{2}=2, \mathrm{t}_{3}=4, \mathrm{t}_{4}=8$ \\
\hline Wielkość próżni [Torr] & $10^{-3}$ \\
\hline Chłodzenie & razem z piecem \\
\hline
\end{tabular}



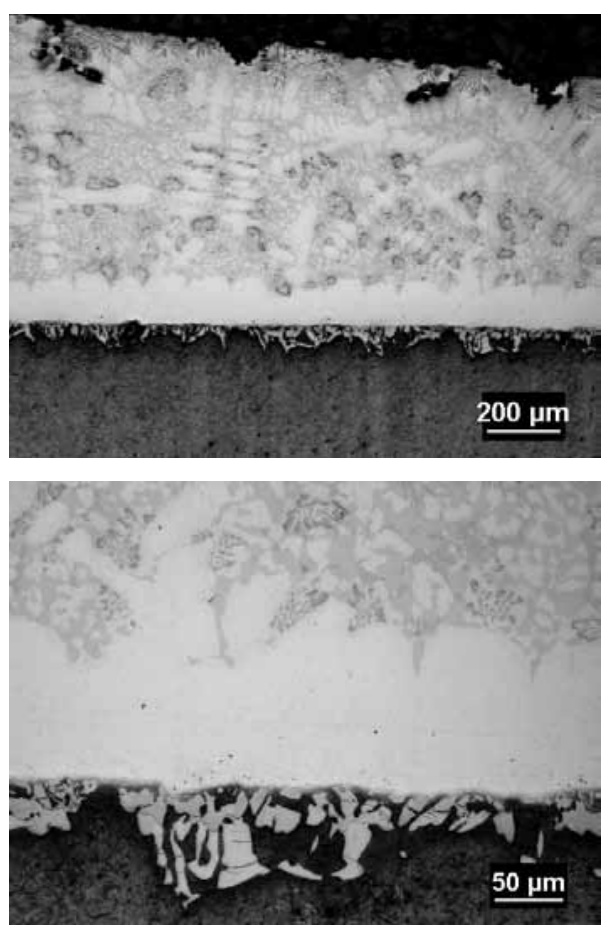

Rys. 5. Zdjęcia mikroskopowe próbki zahartowanej po natapianiu lutem BNi-2 i wygrzewaniu przez 8 godzin

Fig. 5. Microscopic images of the sample hardened after surfacing with BNi-2 and soaking for 8 hours

Stop lutowniczy BNi-2 tworzy z materiałem podłoża fazy międzymetaliczne (nie identyfikowane). W strefie dyfuzji powłoka - podłoże widoczna jest struktura kolumnowa. Wielofazowa powłoka jest zbudowana z trzech stref - ciemnej, szarej i jasnej, o różnej morfologii (rys. 6).

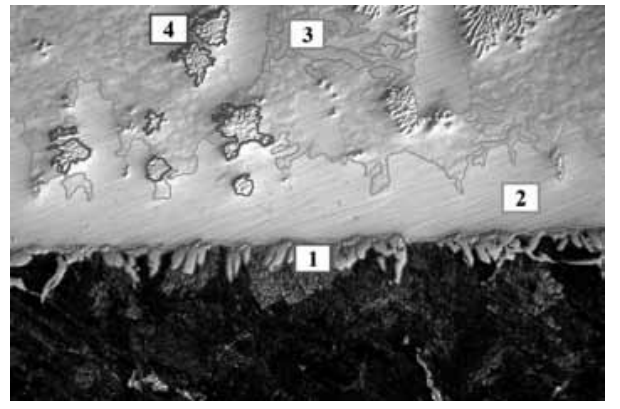

Rys. 6. Oznaczenie stref $w$ powłoce i obszarze dyfuzji dla lutu BNi2: 1 - ziarna słupkowe w strefie dyfuzji, 2 - strefa jasna, 3 - strefa szara, 4 - strefa ciemna

Fig. 6. Determination of areas in the coating and diffusion zone for brazing alloy BNi-2: 1 - columnar grains in diffusion zone, 2 - bright area, 3 - gray area, 4 - dark area

Pomiary twardości wykazały różnice w twardości poszczególnych stref powłoki. Strefa jasna (2) charakteryzuję się najniższą twardością rzędu 220 HV0,025 i jej twardość nie zależy od czasu procesu. Wyższe wartości twardości otrzymano dla strefy szarej (3) - średnia twardość 1135 HV0,025. Z otrzymanych danych wynika, że twardość tej strefy również nie zależy od czasu wygrzewania. Strefa jasna oraz szara stanowi największy udział w powłoce. Strefa ciemna (4) charakteryzuje się najwyższą twardością w powłoce i występuje w postaci wydzieleń o dendrytycznym kształcie. Twardości, jakie osiągają obszary tej strefy, wynoszą od 1600 do ponad 2000 HV0,025, zależnie od czasu procesu. Wraz ze wzrostem czasu obróbki spada twardość strefy ciemnej. Ziarna w strefie dyfuzji (1) mają strukturę kolumnową i rozrastają się w kierunku podłoża. Twardość tych ziarn wynosi od 1200 do ponad 1700 HV0,025. Materiał modyfikowanej stali po hartowaniu wykazuje twardość na poziomie 750 HV0,025 (wartość średnia). Rozkład twardości poszczególnych stref powłoki, ziarn słupkowych w strefie dyfuzji oraz podłoża w zależności od czasu procesu przedstawiono na rysunkach 7 i 8.

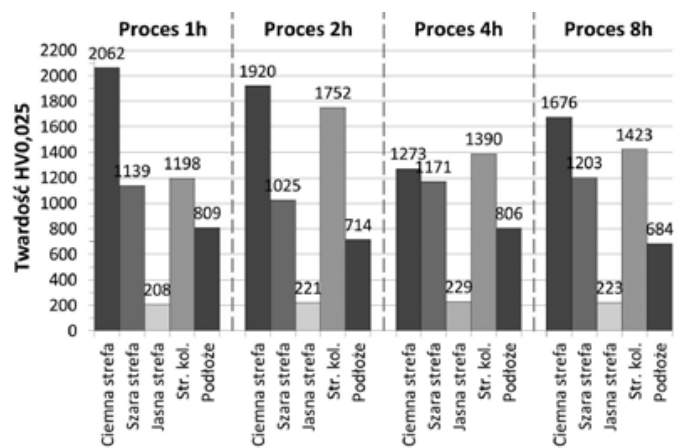

Rys. 7. Wpływ czasu procesu wygrzewania lutu BNi-2 wraz z późniejszym hartowaniem na twardość stref $w$ powłoce, struktury kolumnowej w strefie dyfuzji oraz materiału podłoża

Fig. 7. Influence of the soaking process time of BNi-2 with the hardening to the hardness of areas in the coating, columnar structure in diffusion zone and base metal

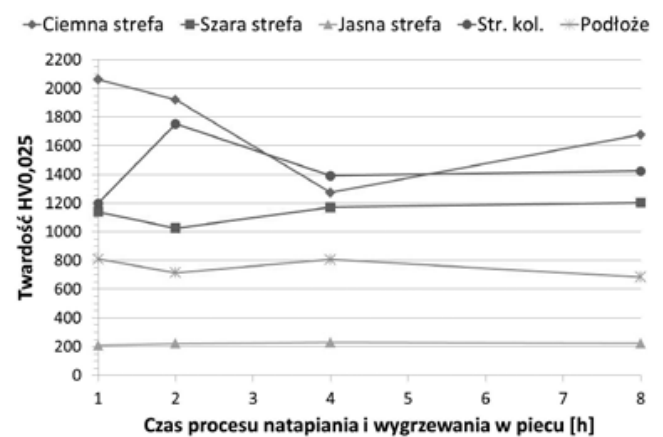

Rys. 8. Wpływ czasu procesu wygrzewania lutu BNi-2 wraz z późniejszym hartowaniem na twardość stref w powłoce, struktury kolumnowej w strefie dyfuzji oraz materiału podłoża

Fig. 8. Influence of the soaking process time of BNi-2 with the hardening to the hardness of areas in the coating, columnar structure in diffusion zone and base metal

Czas procesu natapiania i wygrzewania w piecu próżniowym wpływa na wielkość obszaru struktury kolumnowej w strefie dyfuzji. Wraz ze wzrostem czasu procesu rośnie głębokość, na jaką rozrastają się obszary faz międzymetalicznych. Zależność wielkości ziarn słupkowych od czasu obróbki wyznaczono na podstawie pomiarów maksymalnych wielkości widocznych ziarn $\mathrm{g}_{\max }$ (zgodnie z rysunkiem 9).

Na rysunku 10, w formie wykresu liniowego, przedstawiono zależność wielkości ziarn słupkowych w strefie dyfuzji od czasu wygrzewania i wariantu obróbki. Wraz ze wzrostem czasu obróbki rośnie głębokość, na jaką rozrastają się ziarna w kierunku podłoża. Zależność ta jest jednoznaczna w przypadku wariantu z hartowaniem po procesie wygrzewania. Dla modyfikacji polegającej na samym wygrzewaniu przez 2 godziny zanotowano spadek wielkości ziarn o $5 \mu \mathrm{m}$ w stosunku do obróbki, gdzie czas wynosił 1 godzinę. Dalsze zwiększenie czasu procesu spowodowało rozrost obszarów faz międzymetalicznych na granicy o $45 \mu \mathrm{m}$. 


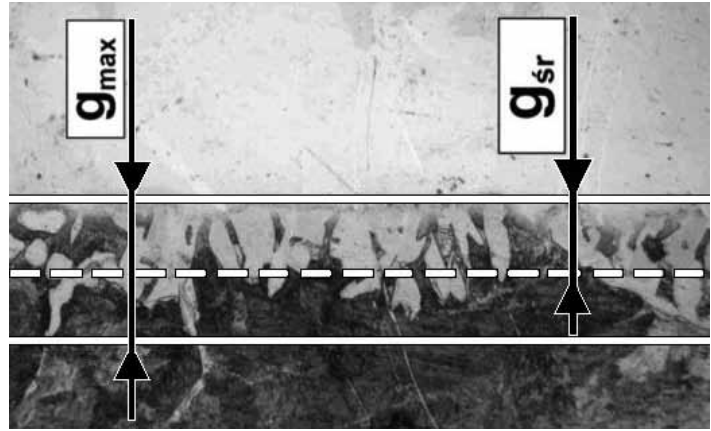

Rys. 9. Oznaczenia maksymalnych i średnich wartości wielkości ziarn słupkowych w strefie dyfuzji

Fig. 9. I Designations of the maximum and average size values of columnar grains in diffusion zone

\section{Podsumowanie}

Wyniki badań wykazały, że lut BNi-2 w postaci pasty może być użyty do modyfikacji powierzchni stali. Jego skład chemiczny zapewnia uzyskanie powłoki zbudowanej z trzech stref, w tym strefy ciemnej i szarej o wysokiej twardości. Ponadto ciekły lut wykazuje powinowactwo metalurgiczne $z$ materiałem podłoża, tworząc strukturę kolumnową w strefie dyfuzji powłoka-podłoże. Powłoka posiada strukturę wolną od wad oraz wykazuje ciągły charakter połączenia z podłożem, niezależnie od czasu procesu.

Przeprowadzone badania wpływu czasu wygrzewania $\mathrm{w}$ piecu próżniowym na zmianę twardości stref $w$ powłoce oraz $w$ obszarze struktury kolumnowej wykazały stabilizację zmian twardości poszczególnych stref wraz z czasem procesu. Stabilizacja następuje dla procesu, gdzie czas wygrzewania wynosi co najmniej 4 godziny i jest związana ze zjawiskiem ujednorodnienia struktury pod wpływem wydłużonego czasu wygrzewania w wysokiej temperaturze.

Z uzyskanych danych wynika, że czas procesu wygrzewania lutu BNi-2 na podłożu stalowym nie powinien być dłuższy niż 2 godziny. Otrzymana wówczas powłoka zbudowana jest z osnowy, w której rozmieszczone są strefy o wysokiej twardości.

Na podstawie wyników badań metalograficznych powłoki BNi-2 otrzymano zależność między głębokością, na jaką wrastają ziarna słupkowe w materiał podłoża a czasem wygrzewania. Wraz ze wzrostem

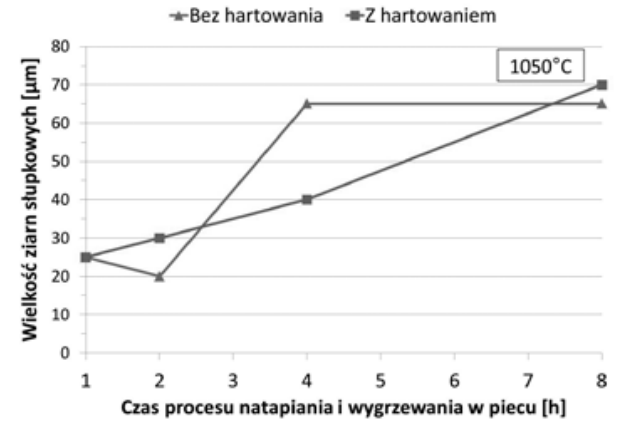

Rys. 10. Zależność wielkości ziarn słupkowych w strefie dyfuzji od czasu procesu wygrzewania i wariantu obróbki

Fig. 10. The dependence between the size of columnar grains in diffusion zone and the soaking time and process variant

czasu obróbki rośnie wielkość ziarn w strefie dyfuzji powłoka - podłoże.

Badania metalograficzne zahartowanych próbek nie wykazały niekorzystnych zmian struktury powłoki. Hartowanie nie spowodowało delaminacji powłoki oraz pogorszenia jakości połączenia z podłożem stalowym.

W badaniach własnych opisano strefy $w$ powłoce jako strefa jasna, szara, ciemna oraz ziarna słupkowe w strefie dyfuzji. Na podstawie analizy literaturowej $[8,9]$, badań mikroskopowych struktury oraz pomiarów twardości można dokonać wstępnego opisu występujących stref. Fazy tworzące ziarna słupkowe w strefie dyfuzji powłoka - podłoże to prawdopodobnie borki $\mathrm{Ni}_{x} \mathrm{~B}_{\mathrm{y}}$ i/lub $\mathrm{Cr}_{\mathrm{x}} \mathrm{B}_{\mathrm{y}}$ bądź borki potrójne $\mathrm{Cr}_{x} \mathrm{Ni}_{y} \mathrm{~B}_{z}$, charakteryzujące się wysoką twardością. Strefa jasna to miękka faza $y$-Ni. Strefa szara to prawdopodobnie borki $\mathrm{Fe}_{\mathrm{x}} \mathrm{B}_{\mathrm{y}}$. Opisywane w pracy ciemne strefy charakteryzują się wysoką twardością oraz wysoką zawartością chromu. Są to borki chromu $\mathrm{Cr}_{\mathrm{x}} \mathrm{B}_{\mathrm{y}}$, najprawdopodobniej $\mathrm{CrB}$.

Do dalszej analizy budowy powłoki BNi-2 pomocne będą układy równowagi fazowej oraz prace badawcze $z$ tej tematyki. W celu potwierdzenia opisanych w pracy faz konieczne jest przeprowadzenie bardziej szczegółowych badań na mikroskopie elektronowym, wyposażonym w analityczny system WDS przeznaczony do zaawansowanej jakościowej i ilościowej analizy składu chemicznego materiałów. System ten pozwala na dokonanie analizy ilościowej dla lekkich pierwiastków takich jak bor.

\section{Literatura}

[1] Granat K.: Wieloskładnikowe stopy Fe-C-Cr-Si odporne na zużycie, przeznaczone na odlewy i warstwy napawane, Oficyna Wydawnicza Politechniki Wrocławskiej, Wrocław 2005.

[2] Dobrzański L. A.: Kształtowanie struktury i własności powierzchni materiałów inżynierskich i biomedycznych, ocsCO, Gliwice 2009.

[3] Młynarczak A.: Technologie i urządzenia do wytwarzania twardych dyfuzyjnych warstw węglikowych na narzędziach i częściach maszyn, Inżynieria Powierzchni, nr 3 2007, s. 30-37.

[4] Babul T., Kondej A., Baranowski M.: Opracowanie technologii selektywnej modyfikacji powierzchni stali z wykorzystaniem lutów na bazie Ni-Cr, Sprawozdanie z Pracy Statutowej, Instytut Mechaniki Precyzyjnej, Warszawa 2014.

[5] Ferenc K.: Spawalnictwo, Wydawnictwa Naukowo-Techniczne, Warszawa 2013.

[6] Knotek O., Lugscheider E.: Brazing filler metals based on reacting Ni-Cr-B-Si alloys, Welding Research Supplement, October 1976, s. 315-318dostępny na rynku w postaci pasty, taśmy oraz folii.

[7] Ou C.L., D. Liaw W., Du Y. Shiue C., R. K.: Brazing of 422 stainless steel using the AWS classification BNi-2 Braze alloy, Journal of Materials Science, Volume 41, Issue 19, October 2006, s. 6353-6361

[8] Ruiz-Vargas, J., Siredey-Schwaller, N., Gey, N., Bocher, P., Hazotte, A.: Microstructure development during isothermal brazing of Ni/BNi-2 couples, Journal of Materials Processing Technology, Volume 213, 2013, s. 20-29. 